\title{
¡Abajo los exámenes! ${ }^{1}$
}

\author{
Mario Bunge ${ }^{2}$
}

Para qué estudian casi todos los estudiantes? ¿Para aprender? No. Estudian para pasar exámenes. Y una vez que los han pasado hacen lo posible por olvidar lo antes posible lo que han aprendido.

Al fin y al cabo, estudian por obligación, no por vocación. ¿Y a quién le interesa recordar información ajena a sus intereses y que no ha requerido más esfuerzo que el de memorizar, acaso sin entender, y seguramente sin profundizar?

Pues de memorizar se trata en los exámenes corrientes. Esta práctica proviene de la escuela autoritaria, en particular religiosa, donde el saber estaba encerrado en textos canónicos que había que leer y recordar.

(Es verdad que en las grandes universidades medievales, tales como las de Bolonia, Padua, Oxford o París, se estimulaba la discusión. Pero toda discusión debía versar sobre asuntos conocidos y debía ceñirse a las Sagradas Escrituras. La meta de la discusión era afinar los argumentos en favor de la doctrina oficial.

Se practicaba la razón pero se la sometía a la fe. La de los escolásticos era una razón enjaulada.)

\section{Fábricas de diplomas}

Hay especialistas en pasar exámenes y otros en enseñar a pasar exámenes. $\mathrm{Ni}$ unos ni otros llegan a destacarse en las disciplinas que aprenden o enseñan, porque nada se aprende bien si no se pone curiosidad, chispa y pasión.

No en vano la corteza cerebral, órgano del conocimiento, está conectada con el órgano límbico, órgano de la emoción, así como con el sistema endocrino, que fabrica algunos de los neurotransmisores.

\footnotetext{
(C) La Nación

1 Este trabajo fue publicado por el diario La Nación el 7 de marzo de 1999 y nos ha parecido más que interesante para ser leído, pensado y discutido entre docentes y alumnos.

$2 \mathrm{El}$ autor es un distinguido físico, docente y filósofo argentino radicado en Canadá. Por su encendida defensa del método científico y sus ácidas críticas al psicoanálisis y a ciertos paradigmas de la posmodernidad ha sido duramente criticado por una parte influyente de la intelectualidad argentina. En general todos sus trabajos generan polémicas que enriquecen cualquier debate.
} 
El régimen escolar estándar es ridículo. Hace que las escuelas no sean centros de aprendizaje sino fábricas de diplomas. Los profesores suministran sin ganas píldoras que apenas alimentan. Los alumnos las tragan sin dejarles rastros perdurables.

Experiencias que deberían ser estimulantes, las de preguntar y redescubrir, se han convertido en una rutina. Un recuerdo que debería ser placentero suele ser penoso.

El remedio está a la vista: si el mal radica en los exámenes, se los elimina. Yo no he tomado exámenes desde que me expatrié en 1963, pese a que no he dejado de enseñar desde entonces. ¿Cómo me las he arreglado? Quien siga leyendo lo sabrá.

Cuando enseñaba física en Argentina y en los Estados Unidos, hacía resolver problemas en el pizarrón. El examen final era a libro abierto. O sea, los estudiantes resolvían problemas con ayuda de todos los libros que quisieran. De este modo, quien había estudiado durante el año (o cuatrimestre) pasaba con seguridad.

Cuando enseñé filosofía en Buenos Aires tomaba microexámenes semanales. Estos consistían en contestar por escrito, a domicilio, un puñado de preguntas. Cada respuesta debía caber en una tarjeta de fichero, de unos 13 centímetros de ancho por 20 de largo. Toda pregunta se discutía en clase con anterioridad, de modo que los estudiantes ya tenían alguna idea acerca de lo que se esperaba de ellos.

O sea, la clase magistral se había convertido en seminario. Y, como es sabido, un seminario laico es un lugar donde los participantes siembran y cosechan ideas. En cuanto al examen oral final, era una farsa: el alumno hacía una exposición sobre un tema convenido de antemano. Lo que le quedaba del curso era lo que había escrito en las tarjetas, para lo cual había buscado información y pensado.

Mis clases de filosofía en Canadá son seminarios que versan sobre problemas tratados en algunos libros y artículos, así como sobre problemas nuevos que plantean los estudiantes o que acabo de leer en publicaciones recientes. 
Para aprobar el curso, los estudiantes tienen que hacer una exposición oral y redactar una monografía sobre un tema diferente del de la exposición. Cuando hay opiniones encontradas y un número suficiente de interesados, la exposición oral se convierte en un debate entre dos equipos. Por ejemplo, uno de los equipos defiende la tesis de que la ciencia y la religión son compatibles, o que hay verdades universales, y el otro defiende la tesis contraria.

Al final intervienen los demás estudiantes. Estos debates son siempre vivaces y concurridos. Enseñan el arte civilizado de discutir racional y ordenadamente.

En cuanto a la monografía, se trata de un trabajo, de unas 20 páginas dactilografiadas, sobre un tema propuesto por el estudiante o sugerido por mí. Por ejemplo: examinar las semejanzas y diferencias entre la ingeniería y la física, o entre la medicina y la biología; analizar el concepto de verdad de hecho, por oposición al de verdad matemática; analizar los méritos y las fallas del deontologismo y del utilitarismo; averiguar si las ciencias presuponen la tesis de la realidad del mundo exterior; determinar si la sociobiología humana es científica; analizar el soporte empírico de la teoría de juegos; estudiar el problema de las leyes en ciencias sociales.

Sobre cualquiera de estos y muchos otros problemas se pueden escribir 20 páginas o 200. De hecho, al cabo de un año un estudiante me presentó todo un libro que envié a una editorial norteamericana, la que lo publicó. Se trata de What Is Wrong with Jung, de Don McGowan (Buffalo, Prometheus Books).

\section{Provocar el aprendizaje}

Sea cual fuere el método de evaluación que se elija, debería provocar aprendizaje y permitir al instructor estimar la habilidad con que los estudiantes aprenden, en lugar de limitarse a poner a prueba la memoria y el grado de sumisión. Las pruebas de competencia no deberían ser sesiones de tortura sino oportunidades para informarse, pensar y lucirse.

En conclusión, ¡abajo los exámenes! 